\title{
Peter Lengyel (1929-2020): A Pioneer Researcher in Protein Synthesis and Interferon Action
}

\author{
Ganes C. Sen ${ }^{1}$ and Bryan R.G. Williams ${ }^{2}$
}

$\mathrm{P}$ eter Lengyel, Emeritus Professor, Department of Molecular Biophysics and Biochemistry, Yale University, and who joined the Department in 1965, passed away at his home in Woodbridge Connecticut on April 21, 2020. He was 91 years old.

Peter was born in Budapest, Hungary, in 1929 and when he grew up he expected to follow several relatives including his grandfather and become a physician. Surprisingly, his grandfather dissuaded him from that path, instead encouraging him to become a scientist and study the scientific basis of medicine. Peter's undergraduate studies were in chemical engineering and after serving in the Hungarian army for 2 years, he enrolled as a biochemistry graduate student at the Semmelweiss University Medical School in Budapest with Professor of Biochemistry, F. B. Straub, who himself was a former student of the Hungarian biochemist and Nobel laureate Albert Szent-Gyorgyi. When Soviet troops brutally suppressed the Hungarian uprising in 1956, Peter fled the country with his partner Suzanna, first to Vienna, where they were married, then to the United States as immigrants.

An interest in the RNA synthesizing enzyme polynucleotide phosphorylase that he had developed in Budapest led him to contact, upon his arrival in New York, its discoverer and subsequent Nobel laureate Severo Ochoa. Peter suggested (Lengyel 2012) that it was Ochoa's sympathy for the Hungarian cause coupled with his own enthusiasm that led him to being accepted as a graduate student with Ochoa at NYU. His graduate studies were focused on deciphering the genetic code in an extraordinarily competitive environment with the laboratories of Nirenberg and Khorana chasing the same goal. After attendance at a lecture given by Sydney Brenner on messenger RNA, Peter suggested to his mentor that perhaps using simple synthetic messengers such as homopolyribonucleotides in cellfree amino acid-incorporating systems could be the key for deciphering of the code. Although Nirenberg was the first to use a cell-free system to show that poly $U$ could stimulate the incorporation of phenylalanine into polyphenylalanine, Peter and his colleagues refined the cell-free system and used randomly ordered synthetic polynucleotides that contained several different nucleotide residues to direct the incorporation of other amino acids. Overall they were able to assign codons for 18

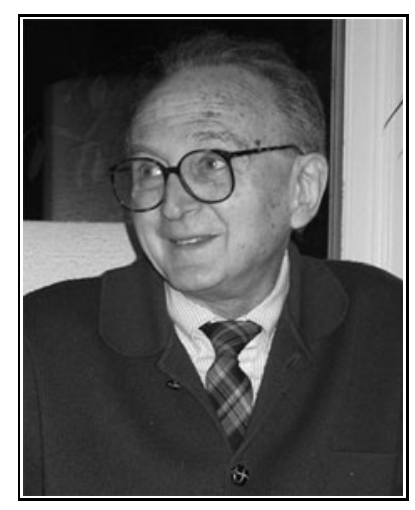

Peter Lengyel

Photo courtesy of Himadri Samanta. amino acids, publish 5 articles in Proceedings of the National Academy of Sciences, and in 1962 Peter was able to submit his thesis entitled "Use of Synthetic Polynucleotides in the Deciphering of the Genetic Code."

After a 1-year postdoctoral fellowship at the Pasteur Institute in the laboratory of Jacques Monod, Peter was recruited to Yale where he spent the remainder of his career. While he continued to work on protein synthesis, Peter was attracted by evidence from Phillip Marcus, Joyce Taylor, and others that interferons may exert their antiviral activity by inhibiting viral protein synthesis. Among other early results, his laboratory demonstrated that extracts from interferon-treated cells contained an endoribonuclease activity that required double-stranded RNA and adenosine triphosphate to degrade viral mRNA. Again he entered a very competitive field that included the laboratories of Ian Kerr and Michel Revel and others that raced to determine the underlying biochemical basis for the inhibitory activity found in extracts from interferon-treated virus-infected cells (Lengyel 2008). Subsequent studies from these and other laboratories revealed the existence of a double-stranded RNA-activated protein kinase that phosphorylated and inhibited the initiation factor of protein synthesis eIF $2 \alpha$ and a family of $2^{\prime} 5^{\prime}$ oligoadenylate synthetases that produced $2^{\prime} 5^{\prime}$ oligoadenylates that activated the latent endonuclease activity first described by Peter's laboratory and now termed RNAseL.

In the later 1970s, Charles Weissmann, a former colleague of Peter from the Ochoa laboratory, engaged with Peter in an attempt to functionally clone mouse interferon using a Xenopus oocyte assay system pioneered by Paula Pitha's laboratory at Johns Hopkins. While Charles moved on to clone human interferons, Peter's interest shifted to the

\footnotetext{
${ }^{1}$ Department of Inflammation and Immunity, Lerner Research Institute, Cleveland Clinic, Cleveland, Ohio, USA.

${ }^{2}$ Department of Molecular and Translational Sciences, Centre for Cancer Research, Hudson Institute of Medical Research, Monash University, Melbourne, Victoria, Australia.
} 
cloning and characterization of interferon-stimulated genes leading to the characterization of the P200 family (Lengyel $2008,2014)$. This turned out to be a treasure trove of interesting proteins with multiple cellular functions. The originally cloned 202 gene (Ifi202) is a member of a cluster of at least 10 genes on mouse chromosome 1 , all inducible by interferon. There exists a homologous set of genes in humans termed the HIN family. Peter's laboratory established that the p202 and p204 proteins have complex mechanisms of action, inhibiting transcription, apoptosis, and cell growth by binding to different transcription factors and proapoptotic proteins. They found that p204 can both modulate differentiation and proliferation, was present in nucleoli, and inhibited ribosomal RNA synthesis. During skeletal and cardiac muscle differentiation, p204 translocates to the cytoplasm where it can bind both $\mathrm{K}$ and H-Rasinhibiting Ras-dependent signaling pathways. This and other findings suggest that p204 could function as a tumor suppressor. Interest in the p200 family members and their human counterparts continues in laboratories around the world. This has been stimulated by the discovery of their role in innate immune sensing in addition to functions already described (Jakobsen and Paludan 2014).

As the children of well-educated Hungarian parents, Peter and Suzanna were fluent in many languages including English and Suzanna became a sought after English editor in her role as a Systems Analyst at the Sterling Memorial Library, Yale University. Both shared passionate interests in art, classical music, and world cultures, and Peter was still able to quote the poems of Goethe late in life. Peter is remembered by his colleagues at Yale as "a beloved and a highly respected member in the Molecular Biophysics and Biochemistry department. He was renowned for his tremendous recall, vast knowledge of science and all things cultural, and his meticulous, precise, and fluent lectures delivered without notes, using only chalk and a blackboard to convey the most complex subjects" (Brown and Hochstrasser 2020).

One of us (G.C.S.) was trained by Peter, and introduced to interferon research. G.C.S. and Peter became very good friends and shared many happy hours together for the past 45 years. Peter loved to take long walks, and at conferences or during visits by G.C.S. to New Haven, they enjoyed these walks together discussing not only science but also all aspects of life. Peter's intellectual curiosity was broad and deep. G.C.S. remembers him explaining at the Smithsonian, the intricacies of ancient Chinese landscape paintings or on the plane to a meeting in Nice, how societal behavior influenced the spread of plague in medieval Europe. As recent immigrants to the United States who grew up elsewhere, Peter and G.C.S. shared admiration for the American people and the natural beauty of the vast nation. It has been distinct privilege of G.C.S. to know Peter as a close friend.

In recognition for his contributions to interferon research in 2008, Peter was awarded Honorary Membership in the International Cytokine and Interferon Society.

Peter's wife Suzanna died in 2019, and son Michael and daughter Carole and 3 grandsons survive him.

\section{References}

Brown NJ and Hochstrasser M. 2020. In rememberance of Peter Lengyel, Professor of MB \& B. Available at: https://mbb yale.edu/news/remembrance-peter-lengyel-professor (accessed June 23, 2020).

Jakobsen MR and Paludan SR. 2014. IFI16: at the interface between innate DNA sensing and genome regulation. Cytokine Growth Factor Rev 25(6):649-655.

Lengyel P. 2008. From RNAse L to the multitalented p200 family proteins: an exploration of the modes of interferon action. J Interferon Cytokine Res 28:273-281.

Lengyel P. 2012. Memories of a senior scientist: on passing the fiftieth anniversary of the beginning of deciphering the genetic code. Ann Rev Microbiol 66:27-38.

Lengyel P. 2014. Wanderings in biochemistry. J Biol Chem 289:19254-19268.

Address correspondence to: Prof. Ganes C. Sen Department of Inflammation and Immunity Lerner Research Institute Cleveland Clinic 9500 Euclid Avenue Cleveland, $\mathrm{OH} 44195$

USA

E-mail: seng@ccf.org 